\title{
Perancangan Dan Pembuatan Kotak Pendingin Berbasis Termoelektrik Untuk Aplikasi Penyimpanan Vaksin Dan Obat-Obatan
}

\author{
Ficho Cahaya Putra ${ }^{1}$, V. Vekky R. Repi ${ }^{1}$ \\ ${ }^{1}$ Program Studi Teknik Fisika, Fakultas Teknik dan Sains, Universitas Nasional, Jl. Sawo Manila, \\ Pejaten, Pasar Minggu, Jakarta Selatan - Jakarta 12520 \\ Korespondensi: vekky_repi@yahoo.com
}

\begin{abstract}
ABSTRAK. Kotak pendingin dengan menggunakan elemen peltier adalah suatu alat yang memanfaatkan elemen peltier (termoelektrik) yang dipergunakan untuk menyimpan produk medis guna untuk dipindahkan dari suatu tempat ke tempat lain agar kualitas tetap terjaga sampai tempat tujuan. Elemen Peltier merupakan media pendingin yang ramah lingkungan karena tidak menggunakan refrigerant sebagai fluida pendinginnya. Maka dari itu dilakukan perancangan dan pembuatan kotak pendingin menggunakan elemen peltier sebagai sistim pendinginnya. Hal ini bertujuan untuk meningkatkan fungsi sistim pendingin pada kotak pendingin agar mencapai suhu kabin sebesar $\pm 18,7^{\circ} \mathrm{C}$ dengan kapasitas beban maksimal 500 $\mathrm{ml}$. Hasil yang dicapai saat pengujian pada beban kosong adalah $18,4^{\circ} \mathrm{C}$, pada beban $100 \mathrm{ml}$ mencapai temperatur $18,4^{\circ} \mathrm{C}$ dan pada beban $250 \mathrm{ml}$ mencapai temperatur $18,7^{\circ} \mathrm{C}$. Data ini berdasarkan suhu di lingkungan berkisar $30^{\circ} \mathrm{C}$.
\end{abstract}

Kata kunci: Kotak pendingin, elemen peltier, cooling box, termoelektrik, urine.

\section{PENDAHULUAN}

Indonesia merupakan salah satu negara dengan jumlah penduduk terbanyak di dunia, yaitu sebanyak 238.569.500 jiwa [1], dan memiliki ribuan pulau-pulau yang terbentang dari sabang sampai merauke. Hal ini didasarkan dengan sulitnya proses pendistribusian medis ke daerah-daerah dalam negeri. Saat ini cold box berisi batu es digunakan untuk membawa obat-obatan, vaksin dan urin yang dinilai cukup efektif untuk distribusi dalam kota, namun efektifitasnya masih dipertanyakan untuk distribusi jarak yang jauh.

Oleh karena itu, dibutuhkan suatu pengembangan suatu alat pendingin yang ramah lingkungan, efektif, dan hemat energi. Berdasarkan beberapa hal di atas, terobosan terbaru pun dapat dilakukan. Kotak pendingin menggunakan elemen peltier dipilih sebagai alternatif karena hemat energi dan memiliki umur pakai yang panjang.

Dengan teknologi kotak pendingin ini mampu menyimpan urin ke daerah terpencil dimana urin memang memerlukan suhu optimum agar tidak rusak dan dapat menghambat pertumbuhan bakteri. Diharapkan dari alat ini adalah mampu mempertahankan suhu yang dibutuhkan dalam proses penyimpanan urin serta dengan adanya alat ini diharapkan mampu menjawab masalah terkait pendistribusian medis ke seluruh pelosok wilayah Indonesia.

\section{LANDASAN TEORI}

Pendingin termoelekrik (thermoelectric cooler) adalah alat pendingin yang menggunakan elemen pertier dalam sistemnya sebagai pompa kalor. Efek peltier timbul apabila dua buah logam yang berbeda disambungkan dan kedua ujung logam tersebut dijaga pada temperatur yang berbeda, selain itu akan ada fenomena lain yang akan terjadi pada dua buah logam yaitu fenomena efek joule, efek fourer, efek peltier dan efek Thomson [2]. Spesifikasi termoelektrik peltier adalah sebagai berikut 
[3], Model: TEC1-12706; Ukuran: 40 x 40 x $4 \mathrm{~mm}$ (penampang $16 \mathrm{~cm}^{2}$, tebal $4 \mathrm{~mm}$ ); Tegangan operasi: 0 s.d. 12 Volt DC; dan Konsumsi Daya Maksimum pada 12 VDC: 72 Watts .

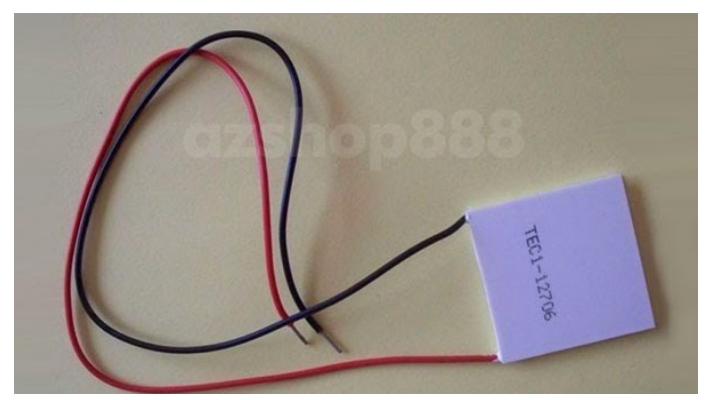

GAMBAR 1. Elemen Peltier.

Prinsip kerja pendingin termoelektrik berdasarkan efek peltier, ketika arus DC dialirkan ke elemen peltier yang terdiri dari beberapa pasang sel semikonduktor tipe $\mathrm{p}$ (semikonduktor yang mempunyai tingkat energi yang lebih rendah) dan tipe n (semikonduktor dengan tingkat energi yang lebih tinggi), akan mengakibatkan salah satu sisi elemen peltier menjadi dingin (kalor diserap) dan sisi lainnya menjadi panas (kalor dilepaskan), seperti gambar 2, sisi elemen peltier yang menjadi sisi panas maupun dingin tergantung dari arah aliran arus listrik [4].

Hal yang menyebabkan sisi dingin elemen peltier menjadi dingin adalah mengalirkan elektron dari tingkat energi yang lebih rendah pada semikonduktor tipe $p$, ke tingkat energi yang lebih tinggi yaitu semikonduktor tipe $\mathrm{n}$. Agar elektron tipe $\mathrm{p}$ yang mempunyai tingkat energi yang lebih rendah dapat mengalir maka elektron menyerap kalor yang mengakibatkan sisi tersebut menjadi dingin. Sedangkan pelepasan kalor ke lingkungan terjadi pada sambungan sisi panas, dimana elektron mengalir dari tingkat energi yang lebih tinggi (semikonduktor tipe $\mathrm{n}$ ) ke tingkat energi yang lebih rendah (semikonduktor tipe $\mathrm{p}$ ), untuk dapat mengalir ke semikonduktor tipe $\mathrm{p}$, kelebihan energi pada tipe $\mathrm{n}$ dibuang ke lingkungan sisi tersebut menjadi panas[5]. Penyerapan kalor dari lingkungan terjadi pada sisi dingin yang kemudian akan dibuang pada sisi panas dari elemen peltier. Sehingga nilai kalor yang dilepaskan pada sisi panas sama dengan nilai kalor yang diserap ditambah dengan daya yang diberikan ke modul.

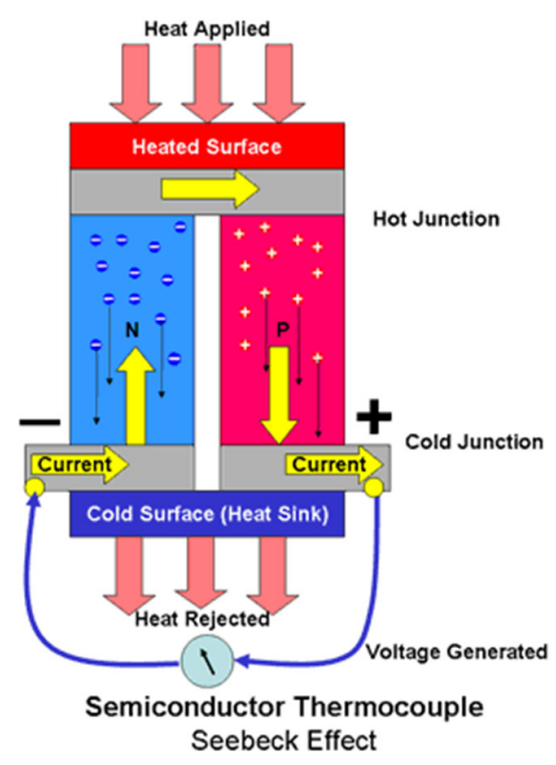

GAMBAR 2. Arah Elektron Pada Modul Elemen Peltier. 
Pada gambar 2, elektron mengalir dari semikonduktor pada tipe $\mathrm{p}$ yang kekurangan energi, menyerap kalor pada bagian yang didinginkan kemudian mengalir ke semikonduktor tipe $n$. Semikonduktor tipe $\mathrm{n}$ yang kelebihan energi membuang energi tersebut ke lingkungan dan mengalir ke semikonduktor tipe $\mathrm{p}$ dan seterusnya [6].

Pendingin termoelektrik memerlukan heat sink yang berfungsi untuk menyerap kalor pada sisi dingin elemen peltier maupun membuang kalor pada sisi panas peltier. Susunan dasar pendingin termoelektrik setidaknya terdiri dari elemen peltier dan heat sink baik pada sisi dingin elemen peltier maupun sisi panas, seperti pada gambar 3. Bagian yang didinginkan dapat lansung dihubungkan dengan sisi dingin elemen peltier maupun dihubungkan terlebih dahulu dengan alat penukar kalor sebelum dihubungkan dengan sisi dingin elemen peltier. Alat penukar kalor tersebut dapat berupa fluida. Kalor yang dihasilkan pada sisi panas elemen peltier disalurkan ke lingkungan melalui udara baik secara konveksi paksa maupun alami atau dengan media pendingin air maupun cairan lainnya [7].

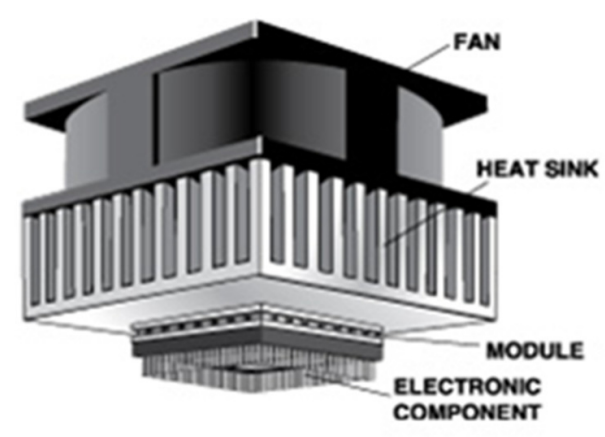

GAMBAR 3. Susunan Dasar Sistem Pendingin Elemen Peltier.

Beban pendinginan yang dimaksud dalam analisis ini adalah beban panas yang berasal dari produk yang didinginkan dan beban panas dari luar yang harus diatasi oleh sistem untuk mencapai temperatur yang diinginkan. Beban pendinginan dari suatu ruangan akan menentukan kapasitas dari mesin pendingin yang digunakan. Terdapat beberapa hal yang perlu diperhatikan dalam menghitung beban pendinginan dari suatu ruangan pendingin yaitu, perbedaan temperatur ruangan yang akan dikondisikan dengan tempertur luar, struktur bahan yang dipakai dalam perancangan, produk yang akan didinginkan,serta hal-hal lainnya yang mempengaruhi beban pendinginan[8]. Beban panas dari luar berasal dari konduksi udara luar dengan dinding. Besarnya beban panas dari luar dapat dihitung dengan menggunakan persamaan (1) sebagai berikut:

$$
Q=A \cdot U \cdot \Delta t
$$

Keterangan :

$\mathrm{Q}=$ Jumlah panas yang dipindahkan (Watt)

$\mathrm{A}=$ Luas Permukaan $\left(\mathrm{m}^{2}\right)$

$\mathrm{U}=$ Angka koefisien perpindahan panas $\left(\mathrm{Watt} / \mathrm{m}^{2}{ }^{0} \mathrm{C}\right)$

$\Delta \mathrm{t}=$ Perbedaan temperatur $\left({ }^{0} \mathrm{C}\right)$

Harga koefisien perpindahan panas total (U) dapat dihitung dengan menggunakan persamaan (2) sebagai berikut:

$$
u=\frac{1}{\frac{1}{f_{1}}+\frac{x}{k_{1}}+\frac{x}{k_{2}}+\frac{x}{k_{n}}+\frac{1}{f_{O}}}
$$


Keterangan:

\begin{tabular}{|c|c|}
\hline & $=$ Harga koefisien perpindahan panas $\left[\mathrm{Watt} / \mathrm{m}^{2}{ }^{\circ} \mathrm{C}\right]$ \\
\hline$k_{1}, k_{2}, . . k_{\mathrm{n}}$ & $=$ Konduktivitas thermal material $\left[\mathrm{Watt} / \mathrm{m} .{ }^{\circ} \mathrm{C}\right]$ \\
\hline $\mathrm{x}$ & $=$ Tebal material $[\mathrm{m}]$ \\
\hline$f_{1}$ & $\begin{aligned}= & \text { Koefisien lapisan udara bagian dalam }\left[\mathrm{Watt} / \mathrm{m}^{2} .{ }^{\circ} \mathrm{C}\right] \\
& \text { Nilai } f_{1} \text { adalah } 1,65 \mathrm{BTU} / \mathrm{h}=9,27 \mathrm{Watt} / \mathrm{m}^{2} .{ }^{\circ} \mathrm{C}\end{aligned}$ \\
\hline$f_{0}$ & $\begin{aligned}= & \text { Koefisien lapisan udara bagian luar }\left[\mathrm{Watt} / \mathrm{cm}^{2} .{ }^{\circ} \mathrm{C}\right] \\
& \text { Nilai } f_{\mathrm{O}} \text { adalah } 4 \mathrm{BTU} / \mathrm{h}=22,7 \mathrm{Watt} / \mathrm{m}^{2} .{ }^{\circ} \mathrm{C}\end{aligned}$ \\
\hline
\end{tabular}

Beban panas dari dalam ruangan merupakan beban panas yang harus dibuang dari ruangan tersebut untuk mencapai temperatur yang diinginkan. Beban panas dari dalam ruangan berasal dari panas produk yang didinginkan. Panas produk adalah beban panas yang harus dibuang untuk mencapai temperatur produk sesuai dengan yang telah ditentukan. Beban panas dari produk dapat dibagi menjadi 2, yaitu beban panas sensibel dan beban panas laten. Perancangan ini beban panas produk hanya berasal dari beban panas sensible yaitu panas yang menyebabkan terjadinya kenaikan dan penurunan temperatur tanpa terjadinya perubahan wujud. Udara didalam ruangan dianggap $27^{\circ} \mathrm{C}$ dan air dikondisikan untuk mencapai temperatur $5^{\circ} \mathrm{C}[9]$.

Beban panas sensibel produk dapat dihitung dengan menggunakan persamaan (3).

$$
Q=m \times c \times \Delta t
$$

Q adalah Jumlah panas yang dipindahkan [kj]; m adalah Berat produk [kg]; c adalah Panas spesifik $\left[\mathrm{kj} / \mathrm{kg} .{ }^{\circ} \mathrm{C}\right]$; dan $\Delta \mathrm{t}$ adalah Perbedaan temperature $\left[{ }^{\circ} \mathrm{C}\right]$.

\section{METODOLOGI PENELITIAN}

Penelitian ini merupakan perancangan awal dari kotak pendingin yang ditekankan pada konsep kotak pendingin dirancang sesederhana mungkin dan diberikan banyak batasan dalam simulasi untuk memudahkan perhitungan. Kemudian dilakukan pengujian untuk dibandingkan terhadap hasil perhitungan.

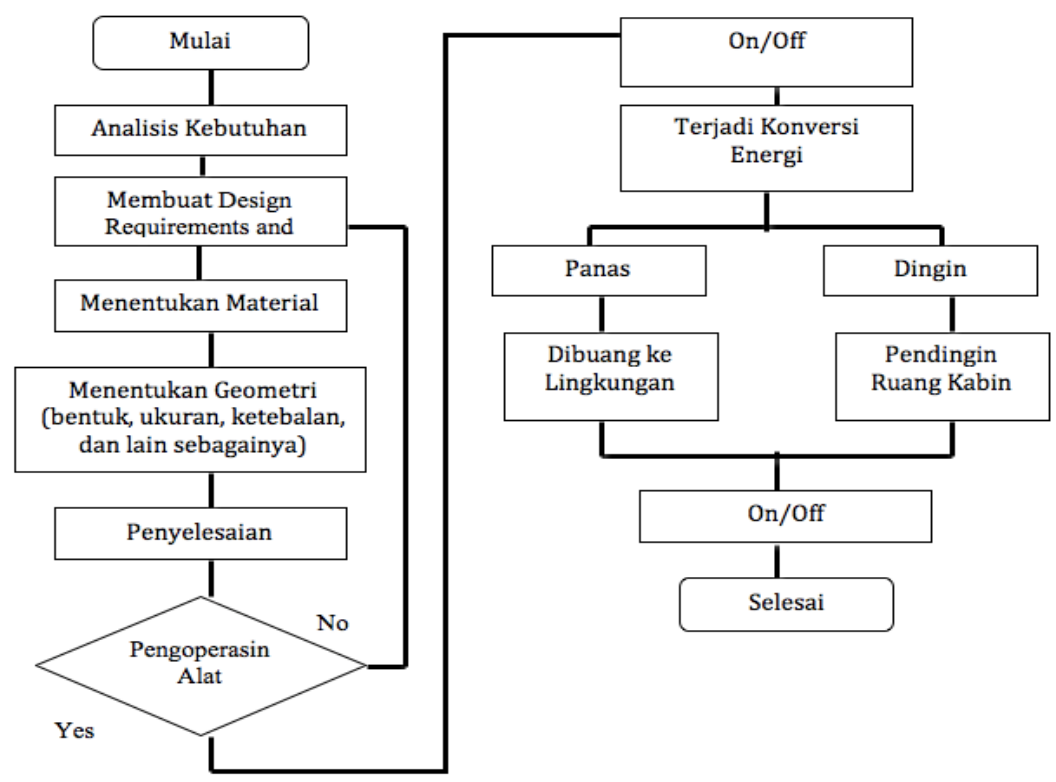

GAMBAR 4. Diagram alir tahap-tahap perancangan. 
Perbedaan yang terjadi akan digunakan untuk evaluasi perancangan selanjutnya. Pada tahap ini dilakukan Design Requirements and Objectives (DR\&O) sebagai bagian penting dalam perancangan. Design Requirements and Objectives atau disingkat DR\&O merupakan pengembangan dari konsep awal perancangan yaitu diinginkan sebuah alat pendingin praktis yang berukuran kecil dan mudah dibawa berpergian.

Dalam mendesain alat kotak pendingin tentunya mengacu pada ukuran komponen-komponen yang digunakan, seperti peltier, kabin alumunium, kotak pendingin utama, sirip alumunium, dan ukuran komponen-komponen pelengkap lainnya. Selain ukuran, hal ini juga mengacu pada nilai estetika dan biaya, karena dari sisi desain alat ini berorientasi pada estetika dan biaya. Setelah seluruh komponen alat telah siap, langkah selanjutnya adalah merakit komponen-komponen tersebut menjadi sebuah kotak pendingin.

\section{HASIL DAN PEMBAHASAN}

Tujuan dari pengujian yang dilakukan adalah untuk mengetahui performance atau unjuk kerja dari kotak pendingin dengan menggunakan sistem pendingin elemen peltier ditinjau dari perubahan temperatur ruang kabin, sehingga dapat diketahui perbandingan unjuk kerja desain saat ini dan desain selanjutnya. Berdasarkan rancangan pengembangan kotak pendingin yang telah dilakukan, spesifikasi teknis kotak pendingin ditunjukkan pada tabel 1.

TABEL 1. Spesifikasi Teknis kotak pendingin.

\begin{tabular}{|c|c|c|}
\hline No & Parameter & Spesifikasi \\
\hline 1 & Voltase & $12 \mathrm{~V}$ \\
\hline 2 & Daya & 42 Watt \\
\hline 3 & Sistem Pendingin & 4 Element peltier (termoelektrik) \\
\hline 4 & Temperatur & $\pm 18^{\circ} \mathrm{C}$ \\
\hline 5 & Volume & $\pm 4,8 \mathrm{~L}$ \\
\hline 6 & Berat & $\pm 5 \mathrm{Kg}$ \\
\hline
\end{tabular}

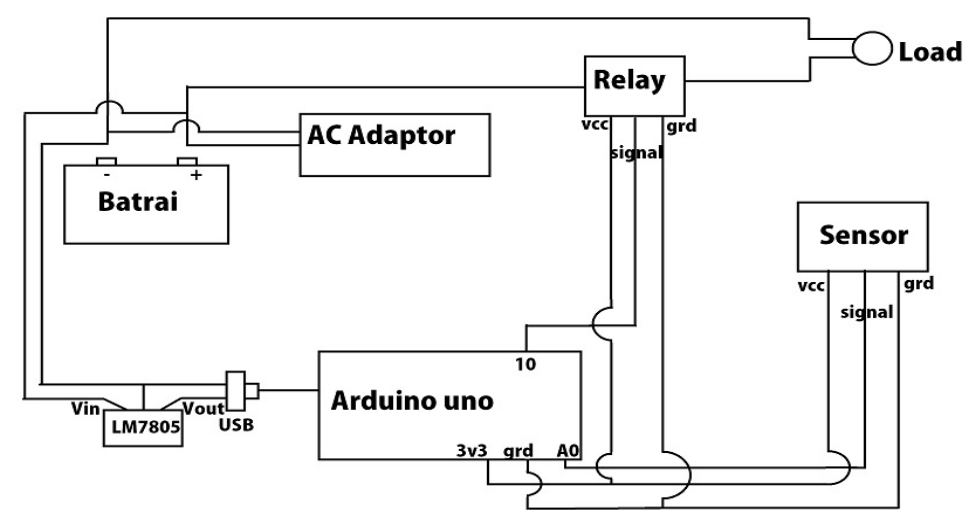

GAMBAR 5. Wiring diagram kotak pendingin.

Pada gambar 5 adalah wiring diagram yaitu skema pengawatan listrik yang dibuat berupa jalur-jalur aliran listrik mulai dari input power sampai output beban dalam satu rangkaian elektronik, sehingga berbentuk suatu sistem control yang telah ditetapkan. Wiring diagram pada gambar 4 dapat diuraikan sebagai berikut:

- Sensor suhu berfungsi untuk membaca suhu dari ruang kabin pendingin kemudian meneruskan sinyal ke mikrokontroler. 
- Mikrokontroler arduino uno yang berfungsi sebagai pengendali relay yang berfungsi sebagai pemutus atau penyambung arus dari batrai ke termoelektrik. Sehingga power batrai yang digunakan lebih efisien.

- Arduino uno diprogram menggunakan software arduino dimana jika suhu diruang kabin mencapai $18^{\circ} \mathrm{C}$ maka dengan otomatis arus dari batrai ke termoelektrik terputus. Dan apabila suhu naik $2^{\circ} \mathrm{C}$ menjadi $20^{\circ} \mathrm{C}$ arus kembali terhubung guna untuk menurunkan suhu diruang kabin kembali. Sehingga penggunaan batrai lebih efisien dan tidak ada energi yang terbuang.

- Disini menggunakan regulator LM7805 yang berfungsi untuk menghasilkan tegangan output stabil 5 volt dengan syarat tegangan input yang diberikan minimal 7-12 volt. Output dari LM7805 ini yang memberikan arus kepada kontroler.

Tabel hasil pengujian adalah data-data dan analisa hasil pengujian kotak pendingin. Penyajian data yang diperoleh dibuat dalam format tabel dan juga digambarkan dalam bentuk grafik yaitu berupa grafik penurunan dan kenaikan temperatur terhadap waktu pendinginan. Pengujian temperatur dilakukan sebanyak tiga kali, selanjutnya diambil nilai rata-rata dari ketiga pengukuran tersebut. Berikut ini disajikan rata-rata nilai hasil dari pengukuran selama 120 menit pada tabel 2.

TABEL 2. Rata-rata nilai temperatur kotak pendingin.

\begin{tabular}{|c|c|c|c|c|c|}
\hline \multirow{2}{*}{ No } & \multirow{2}{*}{ Waktu (menit) } & \multicolumn{4}{|c|}{ Beban (Temperatur ${ }^{\mathbf{0}} \mathbf{C}$ ) } \\
\cline { 3 - 6 } & & $\mathbf{0} \mathbf{~ m l}$ & $\mathbf{1 0 0} \mathbf{~ m l}$ & $\mathbf{2 5 0} \mathbf{~ m l}$ & $\mathbf{5 0 0} \mathbf{~ m l}$ \\
\hline 1 & 0 & 29,6 & 29,6 & 29,6 & 29,6 \\
\hline 2 & 20 & 18,9 & 19,5 & 19,8 & 19,6 \\
\hline 3 & 40 & 18,6 & 19 & 19,4 & 19,3 \\
\hline 4 & 60 & 18,5 & 18,7 & 19 & 19 \\
\hline 5 & 80 & 18,5 & 18,6 & 18,7 & 18,9 \\
\hline 6 & 100 & 18,3 & 18,5 & 18,6 & 18,8 \\
\hline 7 & 120 & 18,4 & 18,4 & 18,7 & 18,7 \\
\hline 8 & (off) 15 & 19,8 & 20,2 & 20,7 & 21,3 \\
\hline 9 & (off) 30 & 21,8 & 22,5 & 22,3 & 22.6 \\
\hline
\end{tabular}

Berikut ini diperlihatkan grafik temperatur dari variasi beban pengujian selama 120 menit dengan tegangan $12 \mathrm{~V}$ dalam kondisi kosong dan kondisi beban urin sebanyak $100 \mathrm{ml}, 250 \mathrm{ml}$, dan $500 \mathrm{ml}$.

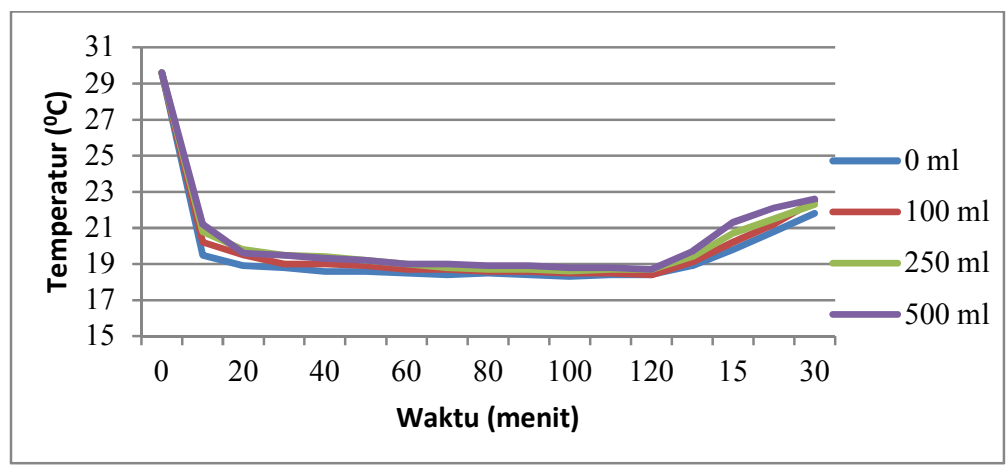

GAMBAR 6. Grafik hasil pengukuran temperatur.

Dari grafik pada gambar 6 dapat dilihat penurunan temperatur yang signifikan pada waktu 20 menit. Selanjutnya dengan penurunan perlahan didapatkan suhu pada menit ke 120 adalah $18,4^{\circ} \mathrm{C}$, dan untuk kondisi off selama 30 menit dicapai temperatur yaitu $21,8^{\circ} \mathrm{C}$. Dari nilai tersebut terlihat kemampuan isolasi kabin untuk menahan kenaikan temperatur pada kondisi off sebesar $3,4^{0} \mathrm{C}$. Pada beban $100 \mathrm{ml}$ terlihat penurunan temperatur pada waktu 20 menit yaitu penurunannya sebesar $19,5^{\circ} \mathrm{C}$ dan suhu minimum yang dicapai adalah $18,4^{\circ} \mathrm{C}$. Pada beban $250 \mathrm{ml}$ terlihat penurunan suhu 
secara signifikan pada waktu 20 menit sebesar $19,8^{\circ} \mathrm{C}$ dan suhu minimum yang dicapai adalah $18,7^{\circ} \mathrm{C}$. Terakhir pada beban $500 \mathrm{ml}$ terlihat penurunan suhu secara signifikan pada waktu 20 menit sebesar $19,6^{\circ} \mathrm{C}$ dan suhu minimum yang dicapai adalah $18,7^{\circ} \mathrm{C}$.

Setelah menempuh waktu 60 menit, suhu akan konstan diangka $18^{\circ} \mathrm{C}$. dimana terjadi penurunan \pm $0,1^{\circ} \mathrm{C}$ per 10 menit. Dan setelah 120 menit sistem mati karena kehabisan energi dari aki. Karena tenaga aki hanya dapat bertahan selama 120 menit. 15 menit pertama setelah sistem mati terjadi kenaikan suhu pada beban kosong $1,4^{\circ} \mathrm{C}$ dan pada beban $100 \mathrm{ml}, 250 \mathrm{ml}$ dan $500 \mathrm{ml}$ mengalami kenaikan $\pm 1,4^{\circ} \mathrm{C}$. Selanjutnya pada 30 menit semenjak sistem mati suhu pada beban kosong menjadi $21,8^{\circ} \mathrm{C}$ dan pada beban $100 \mathrm{ml}$ suhu menjadi $22,5^{\circ} \mathrm{C}$, beban $250 \mathrm{ml}$ suhu menjadi $22,3^{\circ} \mathrm{C}$, dan beban $500 \mathrm{ml}$ suhu menjadi $22,6^{\circ} \mathrm{C}$. Jadi rata-rata kenaikan suhu selama 30 menit semenjak sistem dimatikan adalah $3,5^{\circ} \mathrm{C}$.

\section{Perhitungan Beban Pendingin :}

\section{- Beban Panas Luar}

Beban panas dari luar adalah panas yang mengalir karena adanya perbedaan temperatur udara luar dan dalam kotak pendingin itu sendiri. Oleh karena itu digunakan insulasi guna untuk meminimalisir aliran panas. Seperti dijelaskan sebelumnya, bahan yang digunakan pada kotak pendingin ini menggunakan material acrylic pada bagian ruang kabin, sterofoam pada kotak utama dan alumunium pada bagian luar. Untuk menghitung perpindahan panas dari luar adalah sebagai berikut:

Faktor k akrilik

Faktor k sterofoam

$$
\begin{aligned}
& =0,19 \mathrm{Watt} / \mathrm{m}^{2} .{ }^{0} \mathrm{C} \\
& =0,010 \mathrm{Watt} / \mathrm{m}^{2} .{ }^{0} \mathrm{C}
\end{aligned}
$$

Faktor $\mathrm{k}$ alumunium

$=237 \mathrm{Watt} / \mathrm{m}^{2} .{ }^{0} \mathrm{C}$

Koefisien lapisan udara bagian dalam $=9,27 \mathrm{Watt} / \mathrm{m}^{2}{ }^{0} \mathrm{C}$

Koefisien lapisan udara bagian luar $\quad=22,7 \mathrm{Watt} / \mathrm{m}^{2} .{ }^{0} \mathrm{C}$

$$
\begin{aligned}
& u=\frac{1}{\frac{1}{f_{1}}+\frac{x}{k_{1}}+\frac{x}{k_{2}}+\frac{x}{k_{n}}+\frac{1}{f_{0}}} \quad u=\frac{1}{\frac{1}{9,27}+\frac{0,002}{237}+\frac{0,05}{0,010}+\frac{0,005}{0,19}+\frac{1}{22,7}} \\
& u=\frac{1}{0,108+0,00000844+0,026+0,044} u=\frac{1}{5,178}=0,193 \mathrm{Watt} / \mathrm{m}^{2} .{ }^{0} \mathrm{C}
\end{aligned}
$$

- Luas Permukaan Tiap Bagian Dinding

$$
\begin{array}{lll}
\text { Luas dinding depan } & =\text { belakang }=0,3 \times 0,3=0,09 \mathrm{~m}^{2} \\
\text { Dinding bawah } & =\text { atas } & =0,3 \times 0,2=0,06 \mathrm{~m}^{2} \\
\text { Dinding kiri } & =\text { kanan }=0,3 \times 0,2=0,06 \mathrm{~m}^{2} \\
\text { Luas total } & =0,09+0,09+0,06+0,06+0,06+0,06=2,58 \mathrm{~m}^{2}
\end{array}
$$$$
Q=m \times c \times \Delta t
$$$$
Q=2,58 \times 0,193 \times 15=7,4691 \text { Watt }
$$

- Beban Panas dari Produk

Beban panas dari dalam ruangan merupakan beban panas yang harus dibuang dari ruangan tersebut untuk mencapai temperatur yang diinginkan. Beban panas dari dalam ruangan berasal dari panas produk yang diinginkan. Panas produk adalah beban panas yang harus dibuang untuk mencapai temperatur produk sesuai dengan yang telah ditentukan. Pada penelitian ini alat yang akan didinginkan adalah berupa kotak kapasitas 4,8 liter dengan suhu ruangan $30^{\circ} \mathrm{C}$ dan suhu yang hendak dicapai adalah $15^{\circ} \mathrm{C}$. Kapasitas panas spesifik alumunium $0,92 \mathrm{kj} / \mathrm{kg} .{ }^{0} \mathrm{C}$, maka untuk menghitung beban panas yang dihasilkan adalah sebagai berikut, diketahui :

$$
\mathrm{T}_{\max }=30{ }^{0} \mathrm{C} ; \mathrm{T}_{\min }=15{ }^{\circ} \mathrm{C} ; \Delta \mathrm{T}=15{ }^{\circ} \mathrm{C} ; \mathrm{m}=4,8 \mathrm{~kg} ; \text { dan } \mathrm{c}=0,92 \mathrm{kj} / \mathrm{kg} .{ }^{0} \mathrm{C}
$$




$$
\begin{array}{ll} 
& Q=m \times c \times \Delta t \\
& Q=4,8 \times 0,92 \times 15=66,24 \mathrm{kj}=18,4 \mathrm{Watt} \\
- & \text { Beban Total Pendingin adalah } Q_{\text {total }}=Q_{\text {udara luar }}+Q_{\text {produk }} \\
& Q=7,4691+18,4=25,8691 \mathrm{Watt}
\end{array}
$$

\section{KESIMPULAN}

Pengujian temperatur kotak pendingin ini diperoleh hasil temperatur sebesar $18,4^{\circ} \mathrm{C}$ dengan beban 0 $\mathrm{ml}, 18,6^{\circ} \mathrm{C}$ dengan beban $100 \mathrm{ml}, 18,8^{\circ} \mathrm{C}$ dengan beban $250 \mathrm{ml}$, dan $18,9^{\circ} \mathrm{C}$ dengan beban $500 \mathrm{ml}$ dengan pengujian selama 120 menit. Dengan temperatur $18,4^{\circ} \mathrm{C}$ kotak pendingin ini dapat menyimpan urin selama 120 menit dengan menggunakan tenaga dari aki $12 \mathrm{~V} 3,5 \mathrm{~A}$. Kotak pendingin ini dapat mempertahankan temperaturnya jika telah mencapai suhu yang diinginkan karena adanya sistem pengontrolan arduino uno sehingga pemakaian power dari batrai jadi lebih optimal. Beban pendingin kotak pendingin menggunakan elemen peltier berkapasitas 4,8 liter adalah 25,8691 Watt.

\section{DAFTAR PUSTAKA}

[1] Boothroyd G. and Dewhurst P. Product Design for Manufacture and Assembly, New York: Marcel Dekker, Inc. 2002.

[2] Goldsmid and H. Julian, Introduction to thermoelectricit, USA: Springer. 2010.

[3] Vitriana, Evaluasi Dan Manajemen Medis Inkontinensia Urin, Jakarta: BIKFR. 2002.

[4] Riffat S. and Ma X. "Thermoelectrics: a review of present and potential applications", in Pergamon, 2002, 22.

[5] Mangsur, Pengembangan Cool Box Tipe CB-02 Multi Fungsi Ramah Lingkungan Berbasis Termoelektrik Untuk Kendaraan Roda Dua, Depok: Universitas Indonesia, 2010.

[6] Tim Riset Kesehatan Dasar, Pedoman Pengambilan, Penyimpanan, Pengemasan dan Pengiriman Spesimen Darah. 2007. Jakarta: Riset Kesehatan Dasar, 2007.

[7] Uemura and Kin-ichi, "History of thermoelectricity development" in Journal of Thermoelectricity no. 3, Japan: Komatsu Electronic, 2002.

[8] Anatychuk and Lukyan I., "Solar Thermoelectric Energy Converter" in Journal of Thermoelectricity no. 4, Ukraine: Bukrek publishers, 2013.

[9] R. Umboh, Perancangan Alat Pendingin Portable Menggunakan Elemen Peltier. Manado: UNSRAT.

[10] Sara Godfrey, "An introduction to thermoelectric coolers" in Electronics Cooling, (September 1996). 